1991 Particle Accelerator Conference, San Francisco, 5/6-10/91

BNL -46176

\title{
Calculation of Eddy-currents Induced in a Compact Synchrotron Superconducting Magnet Structure During a Current Ramp ${ }^{1}$
}

\author{
Swarn Kalsi \\ Grumman Space \& Electronics Systems \\ Bethpage, New York 11714 \\ and \\ Richard Heese \\ National Synchrotron Light Source \\ Brookhaven National Laboratory \\ Upton, New York 11973
}

BNL- -46176

DE91 014846

Abstract

Under DARPA sponsorship, a compact Superconducting XRay Light Source (SXIS) is being designed and built by the Brookhaven National Laboratory (BNL) with industry participation from Grumman Corporation and General Dynamics. The SXIS machine employs two $180^{\circ}$ curved 4 tesla stiperconducting dipole magnets. These magnets are required to produce a dipole field for bending the beam but at the same time they must produce finite amounts of higher multipoles which are required for conditioning the beam. In fact uniformity of the field to less than 1 part in 10,000 must be maintained under all operating conditions. When a superconducting magnet is ramped from zero to full field, the changing magnetic field produces eddy-currents in the magnet structure which in turn can produce undesirable multipoles. This paper discusses a simple method for estimating these eddy-currents and their effect on the field harmonics. The paper presents the analysis basis and its application to the SXIS magnet support structure and to the beam chamber components.

\section{INTRODUCTION}

As part of the DoD/DARPA sponsored U.S. National XRay Lithography Program, technology transfer from BNL to Grumman has been underway since the fall of 1988 with the end objective of having Grumman deliver a compact supereonducting $x$-ray light source suitable for application in a semiconductor manufacturing environment. The SXIS is optimized for lithography work for sub-micron high density computer chips, and is about the size of a billiard table (1.5 $m \times 4.0 \mathrm{~m}$ ). The machine has a racetrack configuration with two $180^{\circ}$ bend dipole magnets being designed and built by General Dynamies under a subcontract with Grumman Corporation. Each magnet has 18 photon ports which deliver light peaked at a wave length of 10 Angstroms.

The overall configuration of a superconducting magnet shown in: Fig. 1. It produces a maximum field of $3.85 \mathrm{~T}$ in the beam region. The magnets are air-cored and employ warm beam chambers. In addition to the main dipole field coils, superconducting trim coils are also incorporated for generating quadrupole, sextupole and radial field components. The quality of field in the beam region is very critical. The field must have precisely controlled multipoles up to the decapole level during the whole range of operation of the machine. The superconducting dipole magnets are ramped up from zero field to the full-field $(3.85 \mathrm{~T})$ in 3 minutes during the start-up phase. During this ramping period, eddycurrents are generated in the structural components (magnet cold-mass, cryostat, beam chamber, etc). These eddycurrents could generate undesirable field multipoles with delirious effect on the beam quality.

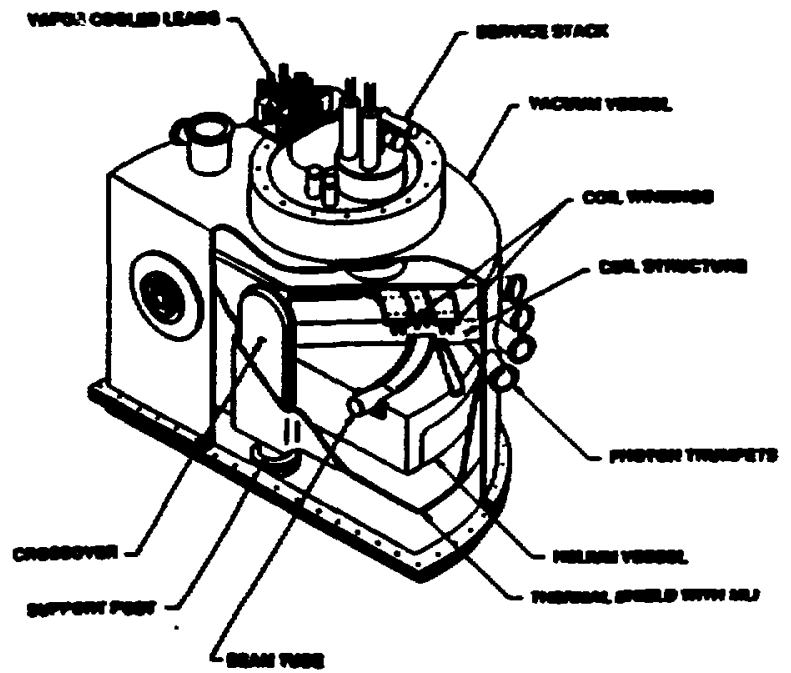

Figure 1: Superconducting Dipole Magnet

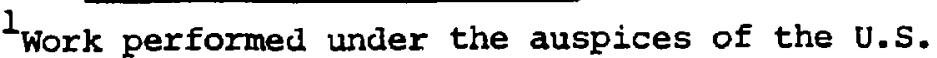
Department of Energy and funded by the U.S. Department of Defense. 
This paper describes an analysis for computing eddy-currents in the structural components of a magnet during a current ramp. These currents are then used for computing the magnetic field in the beam region which is further resolved for obtaining the field multipoles. A sample set of calculations is presented in this paper as an illustration.

\section{ANALYSIS}

Fig. 2 shows the beam chamber assembly cross-section used as an example to describe the calculation technique. The beam chamber assembly consists of a beam chamber, NEG pumps, and ion pumps. During a current ramp in the dipole coils, the field in the magnet bore changes as a function of time. This changing field induces eddy-currents in all conductive components of the chamber assembly.

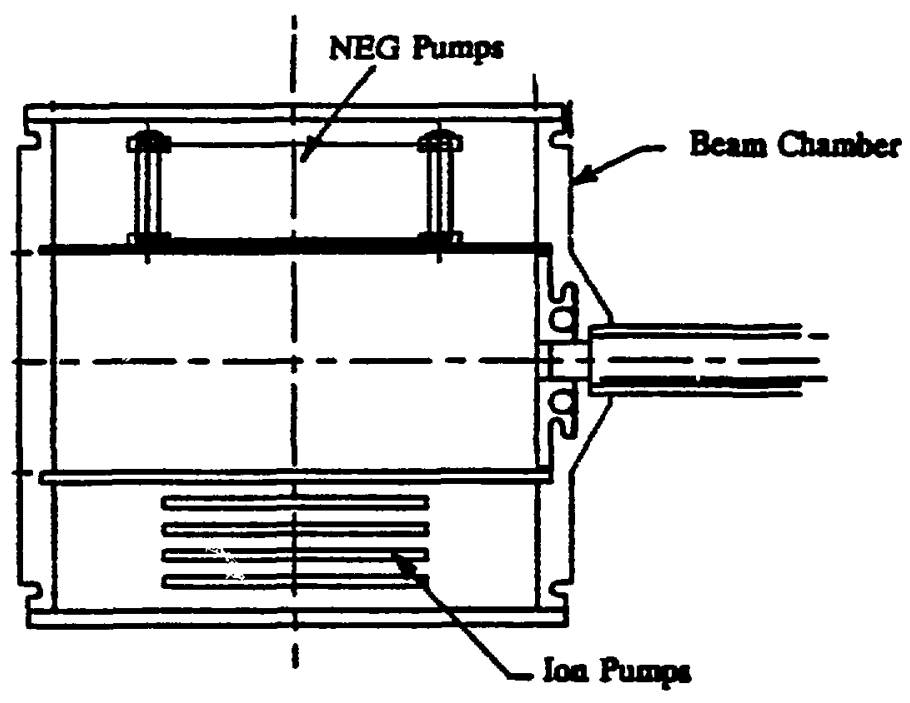

Figure 2: Beam Chamber Assembly

Each dipole is bent $180^{\circ}$. However, for the purpose of calculations, the beam chamber and the dipole coils are assumed to be toroidally continnous. All beam chamber components are made from 304 stainless steel with the exception of ion-pumps which utilize titanium. Each component of the beam chamber is sub-divided (for eddy-current calculations) into a number of circular sub-elements. All dipole coils and the vacuum chamber circuits are inductively coupled to each other. An inductance matrix is calculated which has self- and mutual-inductances for all circuits (including the superconducting coils). Resistance of each circuit is also calculated. Time varying magnetic field due to the dipole current ramp induces voltage in all beam chamber circuits. A set of algebraic equations are developed to satisfy the relationship between the induced currents and the induced voltages. Since the dipoles are only half circles, the net current in all circuits formed by the circular beam chamber elements must sum to zero. Fig 3 shows circular eddy-current circuits which are physically broken and therefore the sum of all circuit currents is constrained to be zero.

The circuit equations to satisfy the above constraint are described below.

$$
\begin{aligned}
& R_{1} I_{1}-R_{1} I_{2}=V_{1}-V_{2} \\
& R_{2} I_{2}-R_{1} I_{3}=V_{2}-V_{3} \\
& \dot{R}_{2-1} I_{2-1}-\dot{R}_{1} I_{2}=V_{4-1}-V_{2} \\
& I_{1}+I_{2}+I_{3}+I_{4}+\ldots . .+I_{1}=0
\end{aligned}
$$

Inductive voltage drop ( $\mathrm{L} \mathrm{dI} / \mathrm{dr}$ ) is ignored because it is negligible for the current ramp values considered in this case. $\mathbf{R}_{\mathbf{l}}, \mathbf{R}_{\mathbf{2}}$ etc. are circuit resistances.

The total woltage $\left(V_{1}, V_{2}\right.$ etc.) induced in each beam chamber circuit is calculated from the current ramp imposed on the superconducting coils with the foilowing relations:

$$
\begin{aligned}
& V_{1}=M_{11} i_{1}+M_{12} i_{2}+M_{13} i_{1}+\ldots . .+M_{11} i_{12} \\
& V_{2}=M_{21} i_{1}+M_{22} i_{2}+M_{2} i_{1}+\ldots . .+M_{2 n} i_{1} \text { etc }
\end{aligned}
$$

where $i_{1}, i_{2}$ etc. are current ramp-rates (rate of change of current with respect to time) and $m$ is the number of superconducting coils. $\mathbf{M}_{1}$ etc. are mutual inductances.

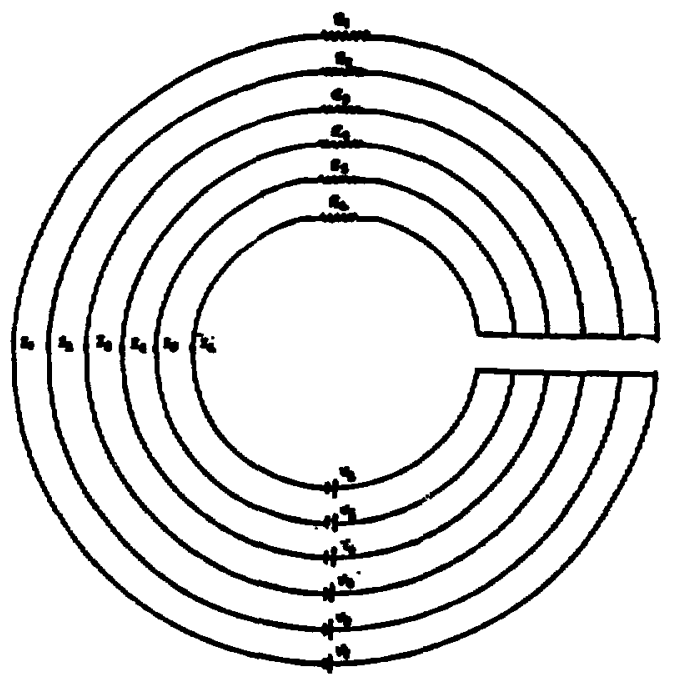

Figure 3: Eddy-current Circuit Concept

For calculating the eddy-currents, first circuit voliages are calculated from Eqn. (2) using the known current ramp-rates in the superconducting coik. These circuit voltages are thea used in Eqn. (1) for calculating n-currents in the beam chamber circuits. These circuit currents are next utilized for calculating magoetic field on the mid-plane of the dipole magnet at 31-radial locations. The fiald can be calculated with any standard code that can handle circular coils with rectangular crose-sections. The magnetic field distribution as a function of radial distance from the beam reference orbit is given in Table-1. 
Table 1

Magnetic Field Distribution

\begin{tabular}{|c|c|c|}
\hline $\begin{array}{l}\text { Redial } \\
\text { Dirtance } \\
\text { (m) }\end{array}$ & $\begin{array}{l}\text { Redial } \\
\text { Rinld } \\
\text { On }\end{array}$ & $\begin{array}{l}\text { Vertical } \\
\text { Field } \\
\text { OT }\end{array}$ \\
\hline-0.030 & $9.000-00$ & $45738-06$ \\
\hline-0.028 & $1.017 \mathrm{E}-07$ & 452018-06 \\
\hline-0.026 & $1.032 \mathrm{e}_{-107}$ & $4,4098-06$ \\
\hline $\begin{array}{l}-0.024 \\
-0.022\end{array}$ & $\begin{array}{l}1.0288-07 \\
1.005 E-07\end{array}$ & $\begin{array}{l}\text { 4.455E-06 } \\
\text { 4.426E-06 }\end{array}$ \\
\hline $\begin{array}{l}-0.022 \\
-0.020\end{array}$ & $\begin{array}{l}1.005 E-07 \\
9.584 E-08\end{array}$ & 4.100E-06 \\
\hline-0.018 & 88831E-08 & 4379E-06 \\
\hline-0.016 & 7.935E-08 & 4361E-06 \\
\hline-0.014 & $6.752 \mathrm{E}-08$ & 4346E-06 \\
\hline-0.012 & $5.348 \mathrm{E}-08$ & 4333E-06 \\
\hline-0.010 & $3.747 E-08$ & 4321E-06 \\
\hline-0.008 & $1.977 \mathrm{E}-08$ & 4.311E-06 \\
\hline-0.006 & $7.427 \mathrm{E}-10$ & 4301E-06 \\
\hline-0.004 & -1.92AE-08 & 42928-06 \\
\hline-6.002 & $-3.978 E-06$ & 4224E-06 \\
\hline 0.004 & $-1.006 \mathrm{E}-07$ & $4258 \mathrm{E}-06$ \\
\hline 0.006 & $-1.192 \mathrm{E}-07$ & 4249E-06 \\
\hline 0.008 & $-1.363 \mathrm{E}-07$ & 4.240E-06 \\
\hline 0.010 & $-1.516 \mathrm{E}-07$ & 4231E-06 \\
\hline 0.012 & $-1.647 \mathbb{E}-07$ & 4.2202E-06 \\
\hline 0.014 & -1.755E-07 & 4.214E- -06 \\
\hline 0.016 & $-1.836 \mathrm{E}-07$ & 4.207E-06 \\
\hline 0.018 & $-1.890 \mathrm{E}-07$ & 4.200E-06 \\
\hline 0.020 & $-1.916 \mathrm{E}-07$ & 4.193E-06 \\
\hline 0.022 & $-1.917 \mathrm{E}-07$ & 4.187E-06 \\
\hline 0.024 & $-1.894 \mathrm{E}-07$ & $4.1002-06$ \\
\hline 0.026 & $-1849 \mathrm{E}-07$ & $4.172 \mathrm{E}-06$ \\
\hline 0.028 & $-1.787 \mathrm{E}-07$ & 4.161E-06 \\
\hline 0.030 & $-1.711 E-07$ & 4.14 \\
\hline
\end{tabular}

Fig. 4 shows the vertical field in a graphic form as a function of the radial distance measured from the reference beam radius. Fig. 5 shows the radial component of the field. The vertical field component in Table -1 is analyzed to determine field multipoles with the LOTUS program.

The calculated harmonies (multipoles) are listed below:

\section{Multipole}

Coefficient

Value

Unit

Dipole

Quadrupole

Sextupole

Octupole

Decapole

$4.273 E-6$
$-3.919 E-6$
$5.665 E-5$
$-2.027 E-2$
1.874

$\mathbf{T}$

$\mathbf{T} / \mathbf{m}$

$T / m^{2}$

$T / \mathbf{m}^{3}$

$T / \mathbf{m}^{4}$

These values of multipoles are small to be of any concern. Since the vacuum tube assembly is asymmetrical about the horizontal plane, the eddy-currents in the beam chamber components produce a net radial field. This field component is $6 \times 10^{-}$which is negligible for all practical purpoces. It is safe to conclude that the eddy-currents induced in the vacuum tube are not likely to impact the beam performance.
Similar calculations could be made for the maget cold mass to study impact of eddy-currents on the field harmonice. The cold mase would hrve to be divided into a aumber of small circuit elements.

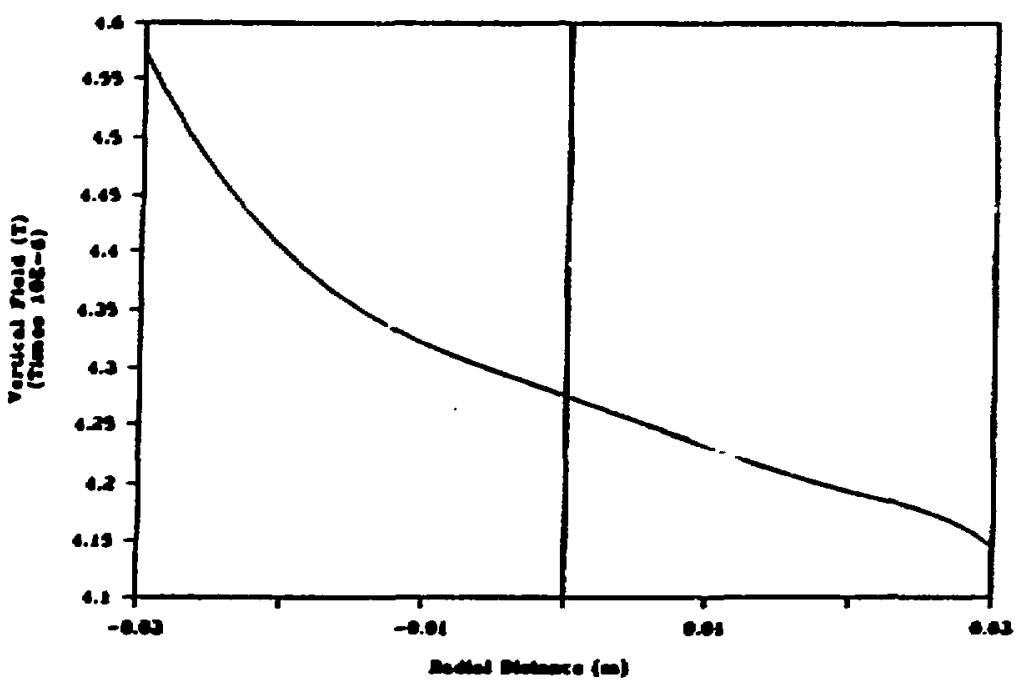

Figure 4: Vertical Field due to Eddy-currents

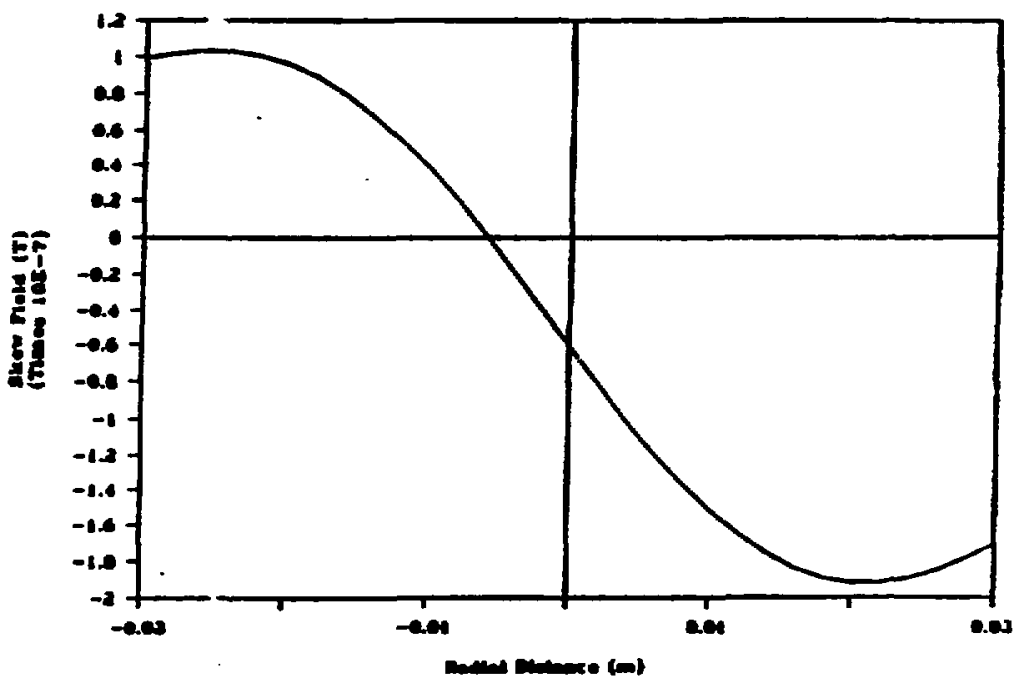

Figure 5: Radial Field due to Eddy-currents

\section{CONCLUSIONS}

A method has been described for calculating eddy-currents in the structural components coupled with the dipole coils. The method is very general and condd be used for studying other similar problems such as currents and forces generated in the cold mase, cyostat and beam tube chamber components during an abrupt quenching of the superconducting magnet coils. 


\section{DISCLAIMER}

This report was prepared as an account of work sponsored by an agency of the United States Government. Neither the United States Government nor any agency thereof, nor any of their employees, makes any warranty, express or implied, or assumes any legal liabiiity or responsibility for the accuracy, completeness, or usefulness of any information, apparatus, product, or process disclosed, or represents that its use would not infringe privately owned rights. Reference herein to any specific commercial product, process, or service by trade name, trademark, manufacturer, or otherwise does not necessarily constitute or imply its endorsement, recommendation, or favoring by the United States Government or any agency thereof. The views and opinions of authors expressed herein do not necessarily state or reflect those of the United States Government or any agency thereof. 